\title{
Force, content and the varieties of subject
}

\author{
Michael Schmitz \\ (penultimate version of a paper forthcoming in a Special Issue on Group Speech Acts \\ in Language \& Communication; please cite printed version)
}

\section{Introduction}

How can a group communicate the positions it takes both regarding what is the case and regarding what to do? In other words, how can it perform speech acts? Group speech acts have been a neglected topic both in speech act theory and the theory of collective intentionality, though recently the interest in them has been growing. Can group speech acts be satisfactorily accounted for by a conservative extension of the framework of traditional speech act theory, or do they require fundamental changes to this framework? In this paper I want to argue that fundamental changes are required. The concerns I will raise all revolve around the notion of a proposition, which is central both to speech act theory and to the received notion of so-called 'propositional attitudes'.

In earlier writings (e.g. Schmitz 2017; 2018a) I have argued that the received framework is biased in three ways:

1) In favor of theoretical, mind (word)-to-world direction of fit, truth-apt, forms of (linguistic and non-linguistic) intentionality as against practical, world-tomind (word) direction of fit, not truth-apt, forms of intentionality;

2) In favor of propositionally and thus also conceptually articulated forms of intentionality as against non-propositional and non-conceptual ones;

3) In favor of individual as against collective forms of intentionality.

The first two biases can also jointly be called the "theory bias", with 1) representing the cognitivist and 2) the intellectualist bias. The theory bias explains why the proposition, as a truth-apt and conceptually articulated representation, has such a central role in the received framework. Obviously, the third form of bias is the one most germane to the topic of group speech acts. However, I want to make plausible in this paper that it is 
also connected with the first two in significant ways, so that in order to construct a satisfactory account of group speech we will have to overcome all three biases.

It will be useful to have a cover term for both intentional states and speech acts, so I will use the term "postures" in this sense. Central to the traditional view is the forcecontent distinction, that is the opposition between the force/mode of postures and their propositional content. Lists like the following are commonly used to introduce speech act theory:

(1) Peter, close the door!

(2) Did Peter close the door?

(3) Peter closed the door.

Think about a situation where these sentences are used to perform speech acts that refer to the same situation: Peter is told to close the door, somebody asks whether he closed it and receives the answer that he did. There is a shared element of these speech acts that identifies the shared situation that these speech acts are about. On the traditional view that element is the proposition. The object or situation in the world that these speech acts are about and that the proposition represents I will call, for lack of a better term, a state of affairs (SOA).

On many versions of the traditional view this same proposition can be the content of an order to make it true, an assertion that it is true, or a question whether it is true. (There are of course further categories of speech acts such as e.g. promises, expressives and declarations, but for purposes of this paper I will focus on directive, assertive and interrogatives act, which correspond to the cross-linguistically most important sentence types of indicative, imperative and interrogative sentences (König and Siemund 2007)). Analogously, a subject could also intend to make this proposition true, know or believe it to be true, or wonder whether it is true. So, the structure of a posture is $F(p)$ for speech acts or $\mathrm{M}(\mathrm{p})$ for intentional states, where " $\mathrm{F}$ " and " $\mathrm{M}$ " represent, respectively, the force or mode of the posture, and " $\mathrm{p}$ " its propositional content.

There is nothing wrong with distinguishing force/mode from other elements of the posture. But this taxonomic version of the force-content distinction (Hanks 2015) is turned into something contentious when it is associated with certain other ideas such as the following: 
1) Propositions are truth value bearers (on many views even the primary ones).

2) The propositional content is the only part of a posture that is representational. The subject and the force/mode of its act are external to content and only represented when the posture is made the object of a report from an external point of view.

3) The content of all postures, and in particular that of speech acts, is conceptual.

1-3) encapsulates (at least some) of the theoretical baggage that is connected to the force-content distinction, which I believe turns it into a dualism, where "dualism" is a pejorative term meaning a distinction that is so exaggerated that it becomes unintelligible how the distinguished elements can function together. I will propose a framework that retains the distinction while overcoming the dualism or dichotomy.

1) embodies the bias for the theoretical over the practical. As truth value bearers propositions belong to the theoretical domain. This is because truth is representational success from theoretical positions, positions like those, for example, of asserting, believing, or hypothesizing. But why should theoretical postures like assertions and beliefs and practical postures like orders, promises and intentions both have truth value bearers as their content, even though we only ascribe truth values to the former? Conversely it is also curious that theoretical postures are themselves truth value bearers and have truth value bearers as their contents. One might suspect that some sort of theoretical doubling is going on here. In the same vein, we might even ask what the difference is really supposed to be between assertions (or statements) on the one hand and propositions on the other. What if anything does asserting that Peter closed the door add to the proposition that Peter closed the door?

A justification for the claim that the shared core of examples like (1)-(3) is a truth value bearer that has been given in the literature is that they all raise the issue of the truth of the same proposition (Searle 1969). However, that the order to close the door raises the issue of the truth of something is only obviously true in that it - in some sense - raises the issue of whether the statement that Peter will close it will turn out to be true. But this does certainly not establish that the statement and the order share a truth-evaluable content. A more neutral and more adequate characterization would be that all these acts raise the issue of the reality of a SOA and take a position with regard to it.

This reality can be affirmed from a theoretical, epistemic point of view or position 
towards the world, based on further theoretical postures such as perceptual experiences, or it can be affirmed from a practical position, based on further practical postures. In the theoretical, mind(word)-to-world case, this SOA is represented as something that is the case, as a fact. In the practical, world-to-mind(word) case, the SOA is represented as something to be done, as a goal, a reality to bring about. But there is no reason why the mere representation of a SOA shared between theoretical and practical postures should already be a truth-value bearer.

Such a representation is only an incomplete part of a bearer of a truth or satisfaction value. As Wittgenstein put it in his mature critique of Frege's version of the forcecontent distinction, it is not "yet a move in the language game" (PI, $\ 22$; his italics). To get a satisfaction-evaluable move, what I have called the position needs to be added to the mere representation of a SOA. That is, it has to be clarified whether the SOA is being represented from an epistemic, cognitive, theoretical position towards the world, so that representational success consists in fitting the representation to the world, or from a practical, conative position, so that representational success consists in fitting the world to the representation.

The point can also be made by considering the relation between the verb stem and the different moods (and intonation contours) with which it occurs (Collins 2017). The stem of a verb like "close" represents a relation, but the mood indicates whether the reality of this relation is affirmed in / with a theoretical or practical mode / force and thus from a theoretical or practical position towards the world. If that is not clarified, if the subject only says something like "Peter close door", we would ask: "What do you mean? Are you telling me that Peter closed the door or are you telling Peter to close it?". Both kinds of speech acts represent the action of Peter closing the door. But only the former represents it as something that is (putatively) the case, as a fact which we are trying to get right, while the latter represents it as a goal, as something to be brought about. 'The same object in the world, the same SOA, in this case Peter's action, can be represented as a fact from a theoretical position towards the world, and representational success from this position is then called "truth"; or it can be represented as a goal from a practical position towards the world, and if representational success from this position is achieved, we say that the posture has been "fulfilled", "realized" or "executed".

\footnotetext{
${ }^{1}$ Does this mean that an action is identical to a fact (or a goal)? No, an action is not identical with a fact (or goal), but it can have the role of being a fact (or goal) when it is represented from a theoretical (or practical) position towards the world. Thanks to an anonymous referee for raising this issue.
} 
There are still different accounts of how the position might be connected to the content representing the SOA, e.g. expressivist, functionalist, or normativist accounts. The distinctive claim I want to defend in this paper is that mode/force is straightforwardly representational, just like propositional content is representational. Now claims to the effect that the subject of a kind of speech act represents or presents ${ }^{2}$ herself, respectively what I have called her "position", in a certain way are intuitively quite plausible and can be frequently found in the literature. Peter Unger, for example, writes: "Asserting that something is so entails not just representing the thing as being so, but representing oneself as knowing that it is." (Unger 1975, 256). More broadly, it is plausible that subjects always have a sense of whether their position towards the world is receptive and epistemic, or active and practical, whether they have, for example, an urge or a sense of obligation to do something, or feel secure in their knowledge that it is the case. But point 2) of the force-content dualism blocks us from even countenancing the most straightforward account of this, namely that the linguistic element that makes a speech act an assertion or other type of speech act, the force indicator, presents the subject's theoretical or practical position regarding the reality of the SOA represented by the rest of the speech act. This paper will be one sustained argument for this straightforward representationalist account and thus against the force-content dualism.

\section{Force, causal self-referentiality and satisfaction conditions}

One consideration in favor of force being representational derives from what Searle (1983) calls the "causal self-referentiality" of certain postures ranging from perceptual and actional experiences to orders. Taking the speech act of ordering as our example, orders are only satisfied, that is, executed or obeyed, if they cause the ordered action. I only execute your order to close the door if I close it because you ordered me. (Moreover, it has to be caused in a specific way; not every causal relation will be an execution relation.) If I did it for independent reasons, I cannot be said to be obeying you. As Searle notes $(1983,86)$, I couldn't be called an obedient person just on the basis of a series of such episodes.

Under the influence of the force-content dichotomy, Searle concluded from this observation that the causal relation between order and ordered action must be represented as part of the propositional content of the order and thus as part of what is

\footnotetext{
${ }^{2}$ I am here treating presentation as a species of representation, following Searle (1983).
} 
ordered. So, on Searle's view, the structure of an order is as follows (adapted from $(1983,86)$; also note the reference to the subject):

I order you (that you close the door by way of obeying this order)

But this view has the counterintuitive consequence that it cannot be said anymore that our order above to Peter to close the door has the same content and is thus directed at the same SOA as the assertion that Peter closed it. This is because on this view it is ordered, but not asserted, that the action be caused by the order. So, this application of the force-content dichotomy actually undermines the intuitive division on which speech act theory and (some versions of) the force-content distinction were originally founded.

At the same time, Searle's observation seems plausible and his reasoning valid given his assumptions. It can be represented as follows:

1) The conditions of satisfaction $(\mathrm{CoS})$ of certain postures (perceptual and actional experiences, memories, orders etc.) require causal relations between these postures and what is e.g. remembered or ordered.

2) Satisfaction conditions must be determined by representational content.

3) Content $=$ propositional content $=$ what is ordered $/$ asserted etc.

4) Conclusion: propositional contents of certain postures must represent causal relations between themselves and what is ordered etc.

Some philosophers might be inclined to doubt 2). But I find myself unable to make sense of the idea that anything in the world could satisfy a posture except relative to conditions set by the content of the mind. I therefore propose to abandon 3) and thus the force-content dichotomy.

The force/mode of a posture is the element that determines the kind of relation to the world that has to obtain for it to be satisfied. It's not because of what is ordered that the order has to cause the ordered action in order to count as obeyed, but because it is an order. The force-content dichotomy makes us commit a fallacy of misplaced information here by locating information in the what- or SOA-content that really belongs to force (Recanati 2007). Instead I propose to extend the notion of content beyond propositional content, beyond what the subjects asserts or orders, to include force or mode content: content that presents the subject's position vis-à-vis the SOA 
identified by what-content. Now I won't try to give an account here of what the position of ordering (or any other position) precisely amounts to. This must be left for another occasion. But some plausible ideas are that in the case at hand, the subject presents itself as knowing what to do and/or as a wanting to bring about the relevant SOA, so that it becomes its goal. So, the reason for the causal element of the CoS is that the subject represents the SOA from a position that is essentially a position of undertaking to cause it, and is aware of itself and presents itself as occupying such a position.

On this view, force is to be understood as a form of self-consciousness. It fits into a tradition of views ranging from Kant, Piaget and P.F. Strawson to contemporary authors such as José Luis Bermúdez, which treat self- and object-consciousness as inextricably linked, as two sides of the same coin. On this kind of view, we are never just aware of objects in the world, but always in relation to ourselves - in the singular case as well as in the plural, which we will soon discuss. For example, in perception and action, we experience objects as spatially, but also causally related to us. We experience ourselves as acting on the world, and the world as impressing itself on us. The idea of force as representational is that we analogously represent our passive, epistemic, descriptive, or active, conative, prescriptive position towards a SOA through force indicators.

\section{Force indicators and non-conceptual content}

One way in which the bias for conceptual over nonconceptual forms of representation comes in is that it makes us likely to misunderstand this idea as the idea that all assertions are equivalent to speech acts performed by utterances of sentences like "I assert that..." or "I order that...". While there has been growing attention to the notion of nonconceptual content in recent decades, the idea that intentional content is conceptual is still strong. In particular, when it comes to language, it is usually taken for granted that linguistically realized content is conceptual. And it hasn't really been discussed in philosophy how such features as intonation contour, grammatical mood or other grammatical markers might represent in contradistinction to representation through lexical items. I propose that basic force indicators such as intonation contour and mood represent non-conceptually. They do not express a conceptual understanding of the subject's position, but a non-conceptual sense of it.

The first and most important difference between conceptual and non-conceptual 
capacities is that the latter do not enable a subject to reflect on its position. ${ }^{3}$ For example, while it may have a sense of knowing, of epistemically confident awareness of a SOA, it may not yet be able to reflect on whether it really knows or merely believes.

A second characteristic feature of non-conceptual representations is their gestaltlike character. Individual features are not clearly separated, but represented through a comparatively undifferentiated whole. So, at the basic level, force is indicated through intonation contour and word order, which modify the whole utterance, and, in synthetic languages, through inflections of the verb, which thus carries several meanings (typically including other inflections such as for tense, aspect etc.), which are not as clearly separated as they would be through corresponding lexical items.

A third characteristic of conceptual content is that logical operations such as negation can operate on it. But negation cannot focus on basic force indicators. One cannot negate grammatical markers of force such as the indicative, imperative or interrogative moods. To perform an illocutionary negation, force needs to be specified lexically and thus conceptually as in e.g. "I am not asserting that it is raining", "I am not ordering you to go", or "I am not asking you whether it is raining". In contrast negations like "It's not raining", "Don't go!", or "Is it not raining?" do not operate on the force indicator, but just on the SOA content (traditionally known as propositional content). ${ }^{4}$ They yield the opposite assertion, directive or question. That is, they negate that things hang together in the world in the way that they are represented in the nonnegated posture, but with the same force. Note that the view that force is representational and can also be specified lexically is well-placed to make sense of illocutionary negation. Through illocutionary negation, a subject indicates its refusal to take the position represented through the force indicator.

\footnotetext{
${ }^{3}$ For a general account of the difference between conceptual and non-conceptual forms of representation, see Schmitz (2012).

${ }^{4}$ Thanks to an anonymous referee for objections which have helped me to clarify my argument here. One objection was that the fact that negation cannot operate e.g. on "the floor" in the sentence "I swept the floor" does not show that "floor" is non-conceptual and another one that actually we can only negate that sentence by means of an auxiliary verb as in "I didn't sweep the floor.". My first point in response is that negation always operates on a (main or auxiliary) verb. We neither negate the floor nor its representation as such, but that it hangs together with the speaker in the sweeping relation. (Negative existentials are a special case in this regard, but in natural language at least negation of existentials also operates on a verb.) Second, negation can still be focused on the different constituents of a sentence, e.g. by stressing them, to indicate that somebody else swept the floor, that the subject did something else with it rather than sweeping it, or that it swept something other than the floor. These are all ways of focusing on different elements of the SOA to indicate that they are specifically responsible for the failure of the SOA to obtain. But as I argue in the main text, there is no way to focus negation on illocutionary force except by introducing an illocutionary verb.
} 
The three features mentioned hang together: because basic force indication is not clearly differentiated, not conceptually articulated, negation cannot focus on it, and it is not sufficient to enable reflection on the kind of position in question. Where to draw the line here between conceptual and non-conceptual representation is certainly largely a terminological question. It may even be more adequate to think in terms of a gradient. In this spirit, let me emphasize that what is important here is that there is a difference in representational format between basic, grammatical force indicators and lexical force indicators rather than how we capture this difference terminologically.

\section{Position, performatives and the self-representation of subjects}

If the mode/force of postures is to be understood in terms of a representation of the subject's position, postures must also involve a representation of the subject itself. Again, it is important that this need not involve a conceptual representation of the subject(s) - assuming that pronouns such as "I" and "we" count as conceptual representations of the subject, but also more extended noun phrases as in "As chancellor of Germany, I...", or "As members of the committee, we... ". Again, I do not want to claim that e.g. "It's raining" is equivalent to "I assert that it is raining". In the individual case, the subject will non-conceptually experience itself as the subject of the posture and of the position it takes. The most important way that this happens for present purposes is through the non-conceptual experience of speaking. The subject experiences itself as speaking certain words and as meaning them and taking a position by doing so, and hearers will in turn experience the subject as the author of its speech act.

A group can also non-conceptually experience itself as the subject of postures. Think, say, about a church congregation saying a prayer or singing together, school children reciting the pledge of allegiance, or a crowd at a demonstration chanting its demands. Or consider possible speech acts performed by the utterance of a sentence like "Go for a walk?". This could be me, standing in front of you, thinking out loud about what I should do. In this case both the subject of the action that I am deliberating about and of the practical commitment I might undertake, is me. But I might also be addressing you, and in this case, we would be the (possible) subject both of the action under consideration and of the joint commitment we might undertake. This difference could be determined entirely non-conceptually. That it is about our action and our 
decision could be determined entirely through our joint attention frame, the tone of my voice, the way I address you etc.

What we discussed under the heading of causal self-referentiality also affects the subject of postures, because there is a question which subject stands in the causal relations to the SOA required by the position. Suppose somebody issues an invitation to an event on behalf of a group, or gives an order or advice in their role as the representative of a certain institution, say the US government. Now sometimes people respond to such speech acts by saying things like "I will do what you tell me because I trust you personally. However, I do not accept the authority of the US government, so let me be clear that I am not doing this because they have ordered me to do this." (Or, conversely, they might clarify that they do not accept the authority of the relevant individual, but rather that of the institution they are representing.) In such a case I think we will be inclined to think that the subject did not fulfill the original order because it did not obey its subject. Extending Searle's point, we could say that even on the basis of a series of such episodes we would not necessarily describe the recipient as obeying the US government and as recognizing its authority.

There are also corresponding cases in the theoretical domain. We might accept testimony from an individual because we epistemically trust them as an individual or because we trust the organization on behalf of which they speak. Are they in an appropriate epistemic (and causal) relation, e.g. knowledge, to the relevant SOA as individuals or as participants (co-subjects) in a group context, say as the anchorperson of a news organization?

I don't want to claim that these considerations are a knockdown argument for the claim that the intentional content of a posture must represent the subject, because one might still argue that the subject need not always be determined through the posture. Perhaps it can be determined through other features of the context. But I do believe it is plausible that in speech acts performed with performative sentences such as the following, the subject of the posture is lexically and thus conceptually represented:

(4) We assert that it rains.

(5) We order you to close the door.

(6) As members of the committee we assert that / order you to / ask you whether... 
Performative sentences and performatives of course have been very important in the history of speech act theory. In How to do things with words Austin famously denied that performatives describe or report illocutionary acts and that they have truth values. Searle in Speech Acts argued that performative prefixes like "I assert" or "We order" are just more explicit illocutionary force indicators. But later several authors, including Kent Bach, Robert Harnish (Bach and Harnish 1979) and Searle (1989) himself proposed accounts according to which performatives have double natures and can be used simultaneously to e.g. order and to assert that one is e.g. asserting or ordering. Bach and Harnish claim that one could e.g. indirectly assert that it rains by directly asserting that one is asserting this. But it is implausible that performatives are only indirectly performances of the acts represented by performative verbs. "Can you close the door?" is a way of indirectly telling me to close it, but there does not seem to be anything indirect about "I order you to close the door". Moreover, as Searle (1989) argued in response to Bach and Harnish, it is hard to see how an assertion can have what he calls the "self-guaranteeing" feature of performatives: that the self-referential labelling of the act as a certain kind of speech act under certain condition guarantees that it is that speech act, with no possibility of the speaker being mistaken or lying about this. A mere assertion that the utterance is such a speech act could not guarantee this.

Searle instead proposes to explain the supposed fact that "a statement can constitute an order" in terms of the subject's intention "that the utterance make it the case that it is an order" (1989, 553; his italics). For Searle, performatives are a species of declarations, acts by which we make something the case by saying that it is the case and which have both mind(word)-to-world and world-to-mind(word) direction of fit. When the intention for our utterance to be an order is appropriately manifested (553), it will be an order. This manifestation can explain how performatives can be self-guaranteeing, while the mere assertion that an utterance is a certain speech act cannot.

Searle's proposal is complex and ingenious. I can't do it full justice here. However, it seems to me that what this talk of "self-guaranteeing" by manifesting intentions ultimately comes down to is that the subject must mean the utterance as an order and manifest its meaning intention by using the performative verb as a force indicator. What guarantees that the utterance is e.g. an order can only be the force indicator. But the intentional structure of the declaration / meaning intention is of course different from that of an order, just as is the assertion discussed earlier: 
(7) I DEC/INT/AS (I/we order you to close the door)

(8) I/We ORDER (you to close the door)

In (7) "order" represents the order position taken by a subject as part of the propositional content, as part of what is declared, intended or asserted. In (8) it functions as a force indicator (symbolized by capitalization) and thus on the present view represents the position taken by the subject. So, Searle does not succeed in explaining how "a statement can constitute an order". What remains is just that performative sentences have two different interpretations, one where expressions like "I/we order" are interpreted as part of the propositional content, and one where they are interpreted as performative prefixes which lexically indicate the subject and the force of the act.

The proposal that force indicators (re)present the positions subjects take can readily explain the intuition that performatives are "self-guaranteeing": I hereby indicate the position I am taking; that's why I can't be mistaken about taking it like I could be had I asserted I had taken it. Nor can I lie about it in the sense of asserting something that I believe to be false. However, it should be noted that I can be insincere in the sense of indicating a position I do not actually occupy, for example by asserting something that I do not know or do not even believe, and in that sense also lie. And while I cannot be mistaken about ordering or asserting, it can of course be a mistake for me to order or assert.

The positions we present by means of lexical force indicators are still the same kind of positions we report or intend. The ambiguity I am talking about here is therefore a functional / structural ambiguity. It might be compared to how the same expression can function both as an adjective and an adverb in languages that do not formally distinguish these different functions such as e.g. German.

What then of the fact that performative sentences are in the indicative? This seems to be the chief motivation for the project of interpreting their performative uses so that they remain truth-evaluable. But I have argued that we cannot simultaneously think of e.g. ordering as represented from a theoretical position presented by the indicative and as indicating the force of the performance. I suggest that in the latter case the indicative becomes idle. Imagine a language where all utterances are performative, where force is always indicated lexically through indicative sentences in the $1^{\text {st }}$ person present. In this scenario I think we should say that the indicative had lost all meaning. In English the 
indicative remains meaningful, but when we interpret the illocutionary verb as the force indicator, as we typically do, that meaning is overridden and does not get activated.

\section{Force, content and the Frege point}

So far, I have been concerned with force as it marks the difference between theoretical and practical positions towards the world, particularly between assertive and directive speech acts. I have argued that while such speech acts may represent the same SOA in the world, as in the classic examples by which SAT is typically introduced, such shared representations are not truth-value bearers. Truth is representational success from a theoretical position towards the world. So, a theoretical position has to be added to what I have called "SOA-content" or "what-content" to yield a truth-value bearer, or a practical position to get a bearer of a practical kind of satisfaction value bearer like "executed". I have further argued that it is both on reflection intuitively plausible and theoretically advantageous to think that this position is actually (re)presented, so that the subject of the speech act presents itself as affirming the reality of this SOA from a theoretical or practical position towards the world, as a fact or as a goal.

To affirm the reality of a SOA is to be committed to this reality. And only something that not merely represents a SOA, but embodies a commitment that things really hang together in the way they are represented, can be the bearer of a truth value (Hanks 2015), or of another satisfaction value. So, truth value bearers must be committal, assertoric and thus forceful. But how is this possible if, as Peter Geach famously put it, "the same proposition can occur asserted as well as unasserted" (1965, 449)? Unasserted it occurs, for example, as the clause of a conditional or disjunction, or in fictional contexts.

What Geach called the "Frege point" seems to necessitate some form of the forcecontent distinction even if I am right that there is no content which can be shared between assertives and directives and which is at the same time truth-evaluable. And in fact, Frege (1956) did not think that what he called "thoughts" and what we nowadays call "propositions" were contained in directives. But even Frege's more limited form of the force-content distinction is inconsistent with the insistence that truth value bearers must be committal and forceful, so I need to address it here. If Frege, Geach and the many who have followed them were right, force indicators could not occur in a great many contexts, and my claim that they are an essential part of any satisfaction-evaluable 
posture would be false. I will argue that on the contrary, my proposal that force indicators are (re)presentational is the only view that can dissolve the apparent problems raised by the Frege point. As I have discussed these issues extensively elsewhere (Schmitz 2018b; manuscripta; manuscriptb), I will keep this discussion brief.

In a nutshell, the problem with the Frege point is that it confounds illocutionary force with different dimensions of meaning or force. As the etymology of the word "proposition" suggests, it points to a variety of contexts in which something is merely put forward for consideration, without commitment to it. But to think that something could not be forceful because it is merely put forward for consideration is to confound the question whether something is merely put forward for consideration with the question what is so put forward. Whether a speech act is assertive or directive is a different question than whether a subject commits to it, or merely puts its forward for discussion; or whether it forms the antecedent or consequent of a conditional, or is a free-standing occurrence; or whether is uttered in jest or on stage, or in earnest etc.

This becomes obvious when we consider the fact that not only assertions, but also plans, orders, advice, obligations, and other practical postures can be put forward for discussion. This is also reflected in the ordinary meaning of "proposition". Google dictionary defines its first sense as "a statement or assertion that expresses a judgement or opinion", and its second as "a suggested scheme or plan of action". Note that common sense apparently is unmoved by the difficulty philosophers see in thinking of a proposition as an assertion. I think common sense is right. It is an illusion that a proposition is something fundamentally different from an assertion. A proposition just is an assertion (or other posture) as being put forward for consideration. It is a posture in a certain role.

But how can a subject put forward an assertion or directive for consideration even though it would not be correct to say that it asserted or directed something? The key to solving this apparent puzzle is to make a distinction between commitment in and commitment to a posture and to see that a posture is put forward for consideration by performing an additional, higher level act, which allows us to present it with the commitment that it contains, while suspending commitment to it. That a commitment is contained in the posture just means that, as I have argued, the posture affirms the reality of the relevant SOA from a theoretical or practical position. That a commitment to the posture may be suspended through a higher-level act can be illustrated through the contrast between conjunction on the one hand and disjunction or conditionalization 
on the other. Conjoining, disjoining and conditionalizing are all higher-level acts that operate on the postures they connect. But while conjoining commits the subject to the conjoined postures, negating, disjoining and conditionalizing only commit it to what I will call an "affirmation function" of the clauses. That is, for example, if the subject affirms the antecedent of the conditional, it is also committed to affirming the consequent.

Note that the conjunction does not trigger the Frege point intuition at all. There is no intuition here that the subject did not assert its clauses. Nor is there an intuition that the minor premise or the conclusion of a modus ponens argument are not assertions or statements. This intuition is only triggered by complexes like conditionals and disjunctions which do not entail their clauses. Because the conditional does not entail its antecedent, we do not want to say that the subject asserted it. And we should not. The subject would be perfectly right to respond by saying: "I only said 'If"! But it does not follow that the antecedent is not an assertion. The subject's response rightly points to the presence of the connective as what makes the difference here. The connective indicates that the antecedent is not entailed by the complex. It is only put forward for consideration. Therefore, the subject is not committed to it. That is sufficient to explain that the subject did not assert it.

That it was merely put forward for consideration does not change the fact that what was put forward is assertive rather than directive in character. It contains a theoretical rather than a practical commitment to the reality of the relevant SOA.

The point can be illustrated by considering so-called mixed inferences:

If it rains, let's take a cab!

It rains.

Let's take a cab!

Here "Make it rain!" cannot detach the antecedent even though it would be true if this order were executed. But the antecedent presents its SOA as a fact, not as a goal, so we need to affirm the reality of this SOA as a fact in order to detach it, and this can only be done from a theoretical position. Affirming its reality as a goal, that is, affirming its realization, is not sufficient.

Moreover, while the modus ponens argument concludes in an assertion or statement, the corresponding modus tollens argument concludes in an order: 
If it rains, let's take a cab!

Let's not take a cab!

It is not raining.

(If you have any doubts this argument is valid, think about it. If you accept the premises, affirming the conclusion is the only way to remain consistent. It is therefore not a valid objection to point out that one might not want to take a cab regardless of whether it rains, say because one does not have the money, because that is inconsistent with the conditional premise. $)^{5}$

These arguments illustrate that different kinds of postures can be connected through logical acts and that these differences affect the validity of arguments. Therefore, we need force indicators to distinguish different kinds of postures, most importantly assertive and directive postures. In contrast, to think that because a posture occurs in a conditional, it should not or cannot contain force indicators, is to confound the function of force indicators with that of the connectives.

That a sign which is used in this way at best becomes idle, can be seen by considering Frege's use of his assertion sign / judgment stroke and, interestingly, also Peter Hanks's use of his cancellation sign and Francois Recanati's (2019) use of Richard M. Hare's (1971) distinction between the tropic and the neustic. This is so even though the view of Frege and contemporary defenders of the force-content distinction (e.g. Green 2018; Soames 2015) is diametrically opposed to that of its critics such as Hanks and Recanati. Frege and his followers think of non-committal occurrences of propositions in conditionals etc. as basic and of force as something that is added through an additional act of the subject, while Hanks and Recanati think that the forceful occurrences are basic and force is cancelled in cancellation contexts, that is, those of conditionals, fiction etc. But both views are subject to the same dilemma:

\footnotetext{
${ }^{5}$ I have heard this objection raised quite frequently from experienced philosophers, who I think would never make this kind of objection with regard to a corresponding purely theoretical argument. For example, if you replace "Let's take a cab!" with "The streets get wet", they wouldn't object that this modus ponens argument is invalid because the streets might be prevented from getting wet in some other way, say by being covered. Why this difference in attitude? I suspect that this is because they are antecedently skeptical about practical deductive inference and thus do not go into 'logic mode' when evaluating arguments with practical postures, and this in turn of course has to do with the fact that they think logic deals with propositions (or indicative sentences), and take for granted that these are fundamentally different from assertions and other postures. Much could be said about this, but here I can only add to what I have said already that in the present context this amounts to begging the question against the argument of this paper.
} 
either the assertion sign or the cancellation sign or the neustic make a difference to meaning and thus to deductive validity, or they don't. If they do, they make the wrong contribution, e.g. invalidating modus ponens. If they don't, they are at best redundant.

In a modus ponens argument, Fregeans will put an assertion sign in front of the conditional, but not its clauses, and in front of the minor premise and the conclusion. (The speaker is serious and it is not a mere supposition etc.) Hanks will use his cancellation sign to mark the force of the clauses of the conditional - but not of the minor premise and the conclusions - as cancelled, making his notation a mirror image of Frege's. The problem is that if these signs contribute to meaning, they will invalidate modus ponens, because the same premise will occur once with, once without the assertion / cancellation sign, and so cannot e.g. detach the antecedent. This is the first horn of the dilemma. So, let us with Hanks (2019), who confronts the dilemma, grasp its second horn, namely that the sign, in his case the cancellation sign, makes no difference to meaning and validity. As Wittgenstein put it in his early critique of Frege, the assertion / cancellation sign is then "logically meaningless" (TLP, $\ 4.442)$. This horn makes transparent that both signs are redundant. At best they repeat something that has already been indicated through the connectives. This should be obvious from the fact that where they go is determined through the connectives: the force of the clauses of conditionals and disjunctions is cancelled, but that of the clauses of conjunctions is not.

The only exception to this is that assertion signs are also put in front of complexes. It will soon become clearer why this is also redundant. But that it is questionable can already be seen from the fact that a claim such as that conjunctions are asserted leads to the result that a conjunction of two statements comprises either three assertions (Hanks 2015), or just one, while the natural answer is clearly two. As John Stuart Mill (1884) pointed out long ago, a team of horses is not another horse. (Both sides err in supposing that there must be an act of asserting the conjunction as a whole; Hanks correctly acknowledges, while the Fregean view denies, that the conjuncts are assertions.)

While Hanks and Recanati are right that propositions are fundamentally forceful, the notion of cancellation and the corresponding signs are therefore not so helpful. As Hanks (2019) admits in response to his critics, terminologically talk of cancellation is misleading: cancellation contexts actually contain more rather than less than other contexts. I suggest that our account can be entirely given in terms of what's more, 
namely the additional higher-level acts: logical acts such as conjoining and conditionalizing, fictional acts of pretense, acts of putting forward for consideration, and so on.

How does the Frege point confusion arise? One source is the tendency to objectify propositions, as something that is the case (in accordance with the theory bias). Its most extreme manifestation is Platonism, the notion that they exist completely independently of subjects, for example in a separate domain like the Fregean 'Third Realm'. Here I will just assert the ontological subjectivity of propositions and postures: "Every posture is somebody's posture". ${ }^{6}$ But objectivist imagery and habits of thought can shape our attitudes even if we reject outright Platonism. One tempting and seemingly innocuous idea is the Fregean one that prior to asserting a proposition we must 'grasp it'. This presents the proposition as something independently existing which we latch onto and the act of grasping as something simple and immediate to which an act of asserting (or judging) must be added. But this is deceptive because when we merely grasp a proposition, we actually perform one of the additional acts we have discussed, acts like conditionalizing or pretending, or perhaps also other acts like reporting the assertion or belief of another, or thinking that a given proposition exists independently of subjects. ${ }^{7}$ Thinking of a posture as something that is merely put forward, but may or may not match reality, is an act more complex and cognitively demanding than just meaning something in the world or understanding what in the world is meant. The child learns to assert and understand free-standing assertions before it grasps conditionals, mere proposals and fictions, and it will take a long time before it understands the Platonist idea that a proposition might exist independently of subjects.

The notion of grasping ${ }^{8}$ thus misconstrues what is actually complex as simple, and creates the illusion that in order to assert or take other positions, an additional act is needed for which we need an additional sign such as Frege's assertion sign. But as it is actually the non-committal 'cancellation context' that contains more, we get from such a context to a commitment by removing the additional sign (or other marker). For

\footnotetext{
${ }^{6}$ I am speaking here of ontological subjectivity in the sense of Searle (e.g. 1992).

${ }^{7}$ I have so far neglected the latter types of acts and will continue to do so because posture reports arguably only report rather than repeat the force / mode of the reported acts (Searle 1983) so that posture verbs function as part of the propositional content rather than as force indicators. ${ }^{8}$ One could also just understand grasping as a cover term for all acts of meaning or understanding a posture. That would be unobjectionable, but wouldn't have the implication that a distinct act of grasping occurs prior to taking a position. For more critical discussion of Frege's notion of grasping see Hanks (2015) and for a recent defense of it Reiland (2019).
} 
example, an act of detaching the antecedent removes the conditional marker and brings with it a commitment to both embedded postures. This is not to deny that there must also be something more present in this situation in order for this act to be warranted. For example, I may assert that it rains on the basis of a perceptual experience and will therefore typically also have a richer and more concrete representation of the antecedent SOA. But the same linguistic acts are performed in both situations.

The subject represents the same SOA, and as I argued above, it must also represent the same position through a force indicator, for else the inference will be invalid - a practical posture like an order cannot detach a theoretical antecedent. The difference is that the subject is now also committed to the represented position because the marker of the higher-level act has been removed. It anticipated a SOA in order to decide what else would be the case then or what to do. It merely considered the SOA, but, again, from a theoretical position as something that might turn out to be the case, as a possible fact rather than a possible goal, and this position, as well as that it was merely anticipated, needed to be indicated. Now that the situation has arrived the assertive act is repeated without the conditional marker so that the subject asserts its reality, triggering the inference.

Terminologically, I thus propose a distinction between performing an assertive act and asserting, or between performing a directive act vs. directing somebody. Using an assertoric force marker always means performing an assertive act, but to accommodate the Frege point intuition I propose to speak of asserting only when the subject is also committed to the assertive act it has performed. I will still call the postures that are indicated through assertive acts "assertions" and those that are indicated through directive acts "directives" even if the subject suspends commitment to them. Other terminologies are certainly possible. We might also just, for example, speak of jokingly vs. non-jokingly asserting, as we often actually do in ordinary speech. Substantively, the following points are crucial. First, force indicators contrast with one another, not with e.g. conditional or fictional markers. Second, they have the same meaning in cancellation as in committal contexts, always representing the subject's position. Third, to assert is not to perform a further act in addition to the assertive act, but to perform that act without performing an additional, higher level act that suspends commitment to it. That is also why we don't need an assertion sign to indicate our commitment e.g. to a conditional or a conjunction. When we put forward a conditional by performing an act of conditionalizing, we are committed to it unless we perform a higher-level act that 
suspends this commitment.

Does this mean that if I e.g. sing in the shower, I am asserting things unless I perform a higher-level act? This may seem implausible. Again, it may even seem I am actually doing less rather than more in such a context. ${ }^{9}$ In response, let me clarify that the claim that an additional act is performed here just means that the context of shower singing is specially marked as non-serious relative to the default, unmarked context of serious language use. So your singing in the shower indicates that your assertive or directive acts are not meant seriously. Or, assuming that you have no communicative intention, you may just be in a special, non-serious shower-singing mood. Both scenarios are consistent with the serious use being psychologically richer, containing more, in other respects.

This account does not seem implausible to me, but if it is to you, note in addition that two claims are being made here. First, that seriousness is a dimensions of force / meaning separate from illocution. Second, that the serious use is the unmarked one relative to the non-serious, so that the latter has to be specially indicated. I defend both claims, but only the first is crucial in the present context. The fundamental point again is that even if I am not serious, there is still a question whether I am non-seriously performing a directive or an assertive act, whether I am e.g. singing "Fly me to the moon!" or "The moon is yellow." That's why the illocutionary dimension has to be marked separately from that of seriousness. This is true even if the non-serious case is not specially marked relative to the serious one.

Contrast this account once more with how the assertion sign is used by Frege, Geach and many others, who conceive of it in such a way that it could not be used in fictional or other 'cancellation' contexts. This in effect means that it would have to indicate the absence of an additional act of e.g. conditionalizing or playacting. But if no further act is performed, the sign is redundant. At the same time, using it cannot prevent such an act. As Donald Davidson pointed out, “...every joker, storyteller, and actor will immediately take advantage" of such a sign $(1984,113)$. So, it is useless either way. Davidson concluded that a force indicator was impossible. But that a force indicator conceived in this way is at best redundant and at worst trying to do something impossible does not mean that there are no force indicators. The mistake is to think that a force indicator would have to exclude conditionalization or lack of seriousness. ${ }^{10}$

\footnotetext{
9 Thanks to a referee for raising this concern.

${ }^{10}$ As a referee points out, Davidson's chief motivation may have been that he thought that no conventional device could indicate force, because force depends on the speaker having the right
} 
As I have argued, this confounds force with other dimensions of meaning which essentially envelop different kinds of force so that e.g. the actor on stage pretends to assert as well as to direct, and the clauses of disjunctions can be assertions as well as directives.

Let me conclude this section by briefly extending this account to questions. Questions are important because they are the most basic way of putting something forward for consideration, and they are often appealed to as such Frege, who emphasizes how they drive scientific inquiry. As we will soon discuss, they are also very important for group speech acts, as joint commitments are characteristically created by means of sentences such as "Go for a walk?". And cross-linguistically, interrogatives are one of three basic sentence types. Can we make sense of this?

My point of departure will be Frege's argument from questions for his version of the force-content distinction, which turns on the significance of an affirmative answer to a yes-no question:

The answer "yes" says the same as an indicative sentence, for in it the thought that was already completely contained in the interrogative sentence is laid down as true. So, a sentence question can be formed from every indicative sentence. [...] An interrogative sentence and an indicative one contain the same thought; but the indicative contains something else as well, namely, the assertion. The interrogative sentence contains something more too, namely a request. Therefore, two things must be distinguished in an indicative sentence: the content which it has in common with the corresponding sentence-question, and the assertion.

(Frege [1918] 1956, 293-94)

Frege's point is essentially that we can only understand how an affirmative answer to a yes-no question can constitute an assertion if both contain the same proposition. But answer and question also contain more: respectively an assertion and a request.

However, this argument can be turned around because it is actually much more straightforward to understand how answering 'yes' can constitute asserting if questions are higher level acts performed on assertions themselves rather than on something supposedly forceless like a proposition. If propositions really are in some sense less than

attitude. But, first, the fact that no convention could guarantee that the speaker is serious is still beside the point. And, second, even if there were no conventional force indicators, this would not support Davidson's alternative proposal to semantically represent 'mood setters' as separate, truthevaluable sentences rather than as what completes any satisfaction-evaluable unit. The issue of conventionality is orthogonal to the issues discussed in this paper. 
assertions, how can affirming the proposition contained in a question add anything to it? We don't ordinarily suppose that we add something to an assertion, plan or proposal by affirming it, assenting to it, or agreeing with it, so why should it be different with propositions? The only exception is that there is a sense in which by e.g. affirming an assertion a new subject is added to it - I become a co-asserter. But it seems clear that the addition of a subject cannot be the same as an addition of force. (When Wittgenstein claimed in the Tractatus (\$ 4.063) that Frege's judgment stroke only indicated that he, Frege, took certain judgements to be true, this was of course meant as an objection.) If on the other hand, as I have argued, propositions just are assertions as put forward for consideration, we can think of yes-no questions as devices for putting forward assertions to invite or even demand yes-no responses to them. On this view, there is no problem about how a 'yes'-response can constitute an assertion.

This view is further supported by the observation that - even though they have almost entirely escaped attention in the theory-biased semantics literature ${ }^{11}$ - there are also practical questions like the aforementioned "Go for a walk?" or "Close the door?". That is, just like logical operators or fictional markers, questions operate on practical as well as theoretical postures. Accordingly, they should be represented as follows:

\section{? AS (dRc) \\ ? ORD (dRc)}

Hanks (2015) proposes that questions are one of three basic types of acts distinguished through their direction of fit, their kind of satisfaction conditions, and how they are reported. Assertive acts have mind-to-world direction of fit, truth conditions and are reported using that-clauses. Directive acts have world-to-mind direction of fit, execution or fulfilment conditions and are reported using to-clauses. Interrogative acts have mind-to-mind direction of fit, answerhood conditions and are reported through whether-clauses.

With the rest of the tradition, Hanks neglects practical questions, but in one way at least their reports fit nicely into his scheme because in contradistinction to theoretical questions, which are reported through whether + finite clauses, practical questions are reported through whether + to-clauses, e.g.:

\footnotetext{
${ }^{11}$ But see Wilson \& Sperber (1988) for a rare exception.
} 
She asked whether the door is closed.

She asked whether to close the door.

This pattern of reports further supports the analysis of questions as higher-level acts that can operate on theoretical or practical acts.

That questions are higher-level acts is also consonant with Hanks's illuminating suggestion that questions have mind-to-mind direction of fit and with the ideas familiar from formal semantic accounts of questions that they have answerhood conditions and (sets of) propositions as their denotation rather than truth values. Questions, one might say, are directed at the world via inviting minds to provide answers.

Through questions subjects indicate positions of wondering whether something is the case or whether to do something and thus of striving for an answer. This can explain why questions invite or even demand answers without reducing them to requests. The Fregean view of questions as requests does not do justice to their nature as higher-level acts and cannot explain them. This becomes obvious if we reformulate questions as requests:

Tell me whether the door is closed!

Tell me whether to close the door!

That we still need to use "whether" here shows that the interrogative element has not been eliminated. That questions can be reformulated as requests to answer questions does not show they are really requests. Finally, the view that questions are requests also cannot straightforwardly make sense of the fact that interrogatives form a separate and cross-linguistically basic category of sentences. If questions were just a subcategory of requests, why should their typical expressions be one of three basic sentence types? The present view can make sense of this: interrogatives rank right after the sentence categories most closely corresponding to assertives and directives not because, like Hanks supposes, they are on all fours with them, but because they perform a crucial function in questioning either assertives or directives (as well as other types of speech acts), in putting forward postures for consideration, opening up new areas of thought prior to commitment and old ones to doubt and criticism. 
6. Applying the account: joint commitment, Moore's paradox and $1^{\text {st }}$ person plural authority

I have argued that in their speech acts and other postures, subjects never just represent a SOA, but also the practical or theoretical position they take regarding the reality of this SOA, and themselves as the subjects of that position. I have also tried to show that the 'Frege point' does not actually stand in the way of this proposal and does not establish the traditional force-content distinction. I now want to further support and develop this perspective by showing how it can solve a puzzle about how joint commitments can be created and how it can respond to two very interesting challenges that Bernhard Schmid (2014a; 2014b; 2018) has raised for the theory of collective intentionality and group speech acts.

How can individuals create joint commitments, and how can they indicate their readiness to enter into such commitments? Margaret Gilbert succinctly describes and critiques the proposal to account for this in terms of either internally or externally conditional statements of matching personal intentions, that is, intentions to the effect that an individual would enter into such a commitment if the other person would also be ready to enter into it:

An internally conditional personal intention is expressible by a statement of the form: "I intend this: to do such-and-such if a certain condition holds." An externally conditional personal intention is expressible, rather, by a statement of the form: "If a certain condition holds, I intend to do such-and-such." In other words, the condition of an externally conditional intention is a condition of the existence of the intention as such.

An externally conditional intention can at the same time be internally conditional. The condition of an externally conditional intention is, in other words, the condition of an actual intention as opposed to one that is categorical in form. The condition of an internally conditional intention is a condition for an intention categorical in form.

Suppose now that in Claire's presence Phyllis remarks loudly: "I intend to do what I can to promote my going for a walk with Claire, if and only if Claire so intends [that is, if and only if Claire intends to do what she can to promote our going for a walk]." Claire then remarks, in similar fashion: "I intend likewise [that is, I intend to do what I can to promote my going for a walk with Phyllis, if and only if she so intends]."

If the intentions expressed here are externally conditional, it is hard to see how the parties can end up with actual personal intentions or commitments. If the intentions are internally conditional, it is hard to see how the parties can end up with categorical commitments of each to do what she can to promote their 
walking together.

(Gilbert 2013, 43f)

The problem is that Phyllis makes her intention to go for a walk together conditional on Claire's intention, while Claire in turn makes her intention conditional on Phyllis's intention. ${ }^{12}$ So neither can ever detach the antecedent of their conditional and arrive at a non-conditional commitment. It seems then that we cannot make sense of how we can go from these conditional I-intentions to a joint commitment. Gilbert only says we must do this via an expression of readiness to commit in this way, but doesn't further explain how this works.

We can explain it in light of our earlier account of questions, in particular practical questions. Questions are the basic means of putting something forward for consideration without yet being committed to it. So, as we noticed earlier, one might just say something like "Go for a walk?", and in a given context it might be nonconceptually indicated that this is a proposal for a joint action. More explicitly, this could be expressed as follows:

(9) Let's go for a walk together, shall we?

(10)? We DIR (we go for a walk together)

(10) is the schematic representation I propose. The speaker puts forward for consideration a directive for joint action, of which the speaker and the hearer would be the subjects. There is thus a commitment to a joint action in what is put forward, but the subjects haven't yet committed to it. If they do, they become co-subjects of a commitment for joint action.

The speaker would typically express her readiness to commit non-conceptually. Her tone, facial and bodily expression would indicate that this is an invitation for a joint action and that she is ready to commit, as Gilbert puts it. (Contrast this with a case where she would raise this question without it having invitational character, for example as an abstract moral question.) However, such a readiness for commitment is not equivalent to a conditional commitment. If she declined to commit after the hearer had agreed, her behavior might be considered rude, weird, or capricious, though not

\footnotetext{
12 In the light of our earlier discussion of logical complexes it could also be argued that the distinction between internally and externally conditional intentions is spurious, but I leave this to the side here to focus on my positive proposal.
} 
necessarily. For example, if she was disappointed that the hearer had hesitated too long or had shown a lack of enthusiasm, we might find it quite natural. In any case, it's not the same as if she had broken a conditional commitment.

I now turn to the two issues raised by Bernhard Schmid. Moore's paradox is wellknown in the singular. In its best-known form it can be exemplified by utterances of sentences like "It rains, but I don't believe that it rains." Such an utterance clearly seems defective, but why exactly? After all, there is no contradiction in supposing that it rains, but that I don't believe it is. I believe that Moore's paradox is a problem for the impersonal, view-from-nowhere construal of the proposition and that by adopting the representationalist account of force developed earlier, we can straightforwardly dissolve the paradox. On the representationalist account, the subject presents itself as having some form of cognitive access to the SOA of it raining; it indicates its position vis-a-vis that SOA. But there is a conflict between presenting oneself as having such access to the SOA and then going on to deny that one believes that it obtains. This explains the defectiveness of the Moore sentence. At the same time, we can appeal to the difference between conceptual and non-conceptual and grammaticalized representations to explain why the Moore sentence is not a plain contradiction. This is because the subject's position is once conceptualized as belief and once indicated through a combination of grammatical markers and intonation. This difference I think can also explain why the two clauses of the sentence embed differently, but this is a task that must be left for another occasion.

Now are there Moore sentences in the plural case? At first sight it may seem that there are none, because e.g., "There is global warming, but we (Republicans) don't believe there is", has a reading that doesn't sound paradoxical. As Schmid points out, we often are members of groups that take positions which aren't true, or at least differ from ours. There is still a tension here though, even if it is not as strong as in the individual case. But this difference in strength can be attributed to the fact that we are comparing the I-intentionality of an individual subject with the We-intentionality of an individual group member. What we should do instead, I suggest, is to compare the speech acts of the individual subject and of the collective, plural subject. Then the difference will disappear.

In the individual case, we have a speech act performed by an individual who takes an individual position in a self-aware way. For the collective case we need to consider a speech act performed by the group, which is also aware of taking a collective position. 
An example for this could be Republican party members saying unison - say, at the Republican convention: "There is global warming, but we don't believe there is." This seems just as defective as in the individual case. In both cases the - singular or collective - subject and its position is first determined non-conceptually. In the individual case, the subject pre-conceptually experiences itself as the subject of the speech act through the actional, motor experience of speaking. In the collective case, the group experiences itself as the speaker through the sensory-motor-emotional experience of speaking jointly. In both cases it is therefore defective to then go on to deny on the conceptual level having taking the position indicated non-conceptually and / or grammatically. The cases are parallel after all and the view that mode is representational, that the individual or collective subject represents itself and its position at different levels of intentionality can explain this.

Let us now ask whether there is also $1^{\text {st }}$ person authority in the singular and the plural case. First, I want to emphasize again that the whole position in this paper is based on the idea that first person authority in the basic case is what one might call "taker's authority". That is, it is not the authority of somebody who has privileged epistemic access to his own mind. Perhaps there are some cases that might be adequately described in these terms, but I submit these are not the basic cases. In the basic cases I have special authority only in the sense that it is up to me take positions by using words in certain ways. In these cases, I don't have special authority with regard to being aware of facts about my mind, but I am aware of taking positions with regard to the reality of SOAs which are represented as facts or goals depending on whether these positions are theoretical or practical.

But what about the plural case? Again one might think there is a disanalogy here because I have no special authority on what the other group members think and thus on what the group thinks (Schmid 2014a). But again, my response is that we need to compare the individual to the collective subject, not only to an individual's we-thoughts and speech acts. Then we will again see that the cases are analogous: the individual takes positions in response to the question what those positions are. The group has likewise special authority because the positions the group members take in collective modes determine the group's position. We must neither look at the positions the group members take in I-mode - that is, their 'private' positions - nor only at the positions a single individual takes in a collective mode. It is the positions the group members take as group members that determine the group's position, and therefore the group - 
conceived of as a plural subject - has first person plural authority.

To anticipate a possible objection, this is not to say that there will always be an answer to the question what the group's position is at any given point. This may be indeterminate if the group has not made up its mind, or if there is perhaps not even an established procedure for determining the group position. But again, I think this does not establish an asymmetry between the individual and the collective case because in the individual case it may likewise be indeterminate what my position is if, say, my ideas regarding a certain issue are very much in flux, or I perhaps haven't thought about it at all.

But isn't this compatible with the group's position being determined in such a way that it would be true to say that the group does not know what it thinks, and isn't this therefore unsatisfactory as a response to Schmid, who thinks that the individual speaker can authoritatively say what he thinks $?^{13}$ For example, an outside observer, who has talked to all members before the group's meeting, might be in a better position to know what will be decided than any of the members. That's true, but I think the same is also true in the individual case. An outside observer might also know better what an individual will decide after having talked to him. But the authority I am trying to explicate here is "taker's authority" - not a special epistemic authority in knowing what is or will be the case with me or with us, but the authority of making up one's mind, of determining positions by taking them in a self-aware way. And with regard to the position the group takes, the words its members speak as members in the meeting, the votes they cast etc. are just as determinative of the group's position as the individual's words of his.

\section{Conclusion: how representationalism can help explain group speech acts ${ }^{14}$}

I have argued that we can make progress on group speech acts by overcoming the force-content dualism and adopting representationalism about force/mode. In every posture, subjects, including collective subjects and role subjects, (re)present positions they take towards the reality of a SOA. Crucial is the idea that the subjects represent themselves as subjects and their positions as positions they take. Neither is represented as an object, much less as something that is the case, though it is certainly represented as part

\footnotetext{
13 Thanks to one of the reviewers for raising this issue.

${ }^{14}$ Thanks to one of the reviewers for suggesting an extra section reviewing the issues about representation.
} 
of reality. Subjects and their positions are not represented as something that is the case (a (putative) fact), nor as something to do (a goal), because a SOA is only a fact or goal relative to a position a subject takes towards it. Now this view is certainly contentious because our concept of representation is heavily biased in ways which I try to capture with the concept of "theory bias", which is a double bias which encompasses both the cognitivist bias for theoretical over practical representation and the intellectualist bias for conceptual over non-conceptual representation.

There certainly are fundamental doubts about the idea that I- and we-awareness and mode/force can be understood representationalistically - as what I have called "subject mode representation" and "position representation" - and in the conclusion to this paper I want to briefly address some of the most important ones in the light of the argument given so far. Isn't, one might ask, what we are talking about here a matter of the being of the subject, of what kind of subject it is and how it is, and of expressing this being in speech rather than about representing it? And isn't force essentially about such things as communication and normative status, so that it may even seem to be a category error to think that it could be representational ${ }^{15}$ Moreover, does it even make sense to speak of representation if misrepresentation isn't possible as some have argued is the case for "I" and "we" and perhaps also for at least some uses of force indicators, which may be "self-guaranteeing"?

These and similar doubts come from a variety of philosophical traditions, from phenomenology, but also from Anscombe's Wittgenstein-inspired qualms about "I" as a referring expression. Wittgenstein also pioneered the thought that at least certain parts of pain language were an expression of pain rather than a report of it, and there is a line that goes from there to the variety of contemporary forms of expressivism. And last, but not least, the entire tradition of speech act theory is based on the force-content dichotomy.

There is one central motivation for most of these tendencies that I wholeheartedly agree with, namely the rejection of the broadly Cartesian notion that we are primarily related to our mental states (however conceived) as objects, more precisely as objects of some kind of immediate epistemic awareness. However, I think it is mistake to throw out the baby of self-representation with the Cartesian bathwater. The main point of this article has been to articulate an alternative picture, according to which there is an awareness of the subject as subject, essentially in relation to objects,

${ }^{15}$ This concern was pressed by a reviewer for the journal. 
but not as an object, and an awareness of mental states not as something one finds but as a position that one takes, and to take some steps towards showing that this picture is also more appropriate for understanding group speech acts than the traditional one.

Does it make sense to think of subject mode and position mode/force in the same breath? Should therefore the we-mode even be called a "mode" (Schmid 2017)? I think it does make sense. To intend or believe something is to represent a SOA from a certain practical or theoretical perspective, or, as I have called it, position, and force is the linguistic expression of that. To represent it in a we-mode or role mode is to represent it from a perspective of identification with a group and/or a role one has in an institutional context, and as I have argued this also has a linguistic expression.

But isn't it a category mistake to think of force in representationalist terms, as force is defined in terms of communicative function and/or normative status? Some theoretical characterizations may be incompatible with the idea that mode/force is representational, but this is not sufficient to show that thinking of the relevant phenomena in this way is a category error. Illocutionary force is primarily defined as what e.g. distinguishes assertions from directives. Moreover, there is no obvious incompatibility between thinking about force in terms of communicative function and normative status one the one hand and in terms of representation on the other. On the contrary, one might think a representationalist account of force as presenting positions will be especially well placed to explain both communication and normative status, as the subject's position is both part of what is communicated and that in virtue of which it has powers and obligations. For example, by asserting both individual and collective subjects communicate positions of knowledge and incur the obligations of such positions.

But isn't it true that one can't misrepresent with "I" and "we" and with (at least some uses of) force markers, and that "if there are conditions of satisfaction, there has to be the possibility of dissatisfaction" (Schmid 2017, 90), so that we should conclude these expressions don't represent after all? I do not think it is obvious that the premise is true. It might be argued that at least "we" may misrepresent in some of the cases discussed earlier and that force markers can also misrepresent, e.g. in cases of insincerity, but possibly in other cases as well. And even granting the premise, at least for the sake of argument, it is not clear the conclusion follows. One may counter that the expressions in question are in good company. It is also not obvious that indexicals like "here", "now" etc. can misrepresent, but most wouldn't conclude that they don't 
represent at all. Moreover, they have an essential role in determining CoS by picking out objects in relation to the subject. I have argued that force indicators have a similar role in determining CoS by determining the relation that has to hold between a subject and the relevant SOA, and that this further extends to subject mode, as it is also essential for $\mathrm{CoS}$ whether such a relation holds between an individual as an individual, or as a member of a group or an occupant of an institutional role.

What about the idea that subjectivity, including collective subjectivity, is just about the being of the subject(s), so that e.g. "plural pre-reflective self-awareness is what plural subjects are" (Schmid 2017, 91; his italics)? Here I need to be clear that on my understanding a subject just is a creature or person and a group is a collection of such subjects as related through relations of co-subjectivity, of jointly taking positions. I thus agree that mental states are essential to both individual and collective subjects, but still reject the identification of these subjects with something purely mental. And I would argue that how their mental states and their linguistic expressions can turn individual subjects into co- and thus into collective subjects is much more straightforward to understand if the relevant forms of collective mind are representational. The crucial claim here is that to experience and represent others as co-subjects is different from merely representing them as objects. For example, at the pre-reflective, or as I like to think of it, preconceptual level of joint attention, we bond with others over objects we experience together (Schmitz 2015). Against the background of this form of co-subjectivity we can then undertake conceptual level joint commitments in the way I have characterized, by putting them forward for consideration, typically through a question, and then coaffirming them. This is irreducibly a joint commitment which creates a plural subject, but how could it be created if its co-subject were not represented as such, as a "we"? Finally, this commitment is created by affirming a representation which is not a representation of what is the case, but of what to do, a representation of a position the co-subjects take by affirming it.

The suggestion that in every posture both the subject and its position are represented and that we need to overcome the force-content distinction is certainly a radical break with traditional speech act theory which raises many questions, not all of which I have been able to answer in this article. But I hope to have made a case that it also has a lot of potential for explaining speech acts in general and group speech acts in particular and deserves to be taken seriously. 


\section{Acknowledgments}

Thanks to the participants of the Vienna workshop on group speech acts, of a workshop in Hradec Králové, and of an Academia.edu session on an earlier version of this paper. In particular, I would like to thank Ingvar Johannsson, Kirk Ludwig, Jacob Mackey, Anthonie Meijer, Leo Townsend, Hans Bernhard Schmid, Preston Stovall and Xiaoxi Wu. Special thanks to two anonymous referees for Language \& Communication for very rich and challenging comments.

\section{References}

Bach, Kent, and Robert M. Harnish. 1979. Linguistic Communication and Speech Acts. MIT Press.

Collins, John. 2017. "The Redundancy of the Act." Synthese, 1-27. https://doi.org/10.1007/s11229-017-1382-3.

Davidson, Donald. 1984. Inquiries Into Truth And Interpretation. Oxford: Oxford University Press.

Frege, Gottlob. 1956. “The Thought: A Logical Inquiry.” Translated by A. M. Quinton and M. Quinton,. Mind 65 (259): 289-311.

Geach, Peter T. 1965. "Assertion." The Philosophical Review 74 (4): 449-465.

Gilbert, Margaret. 2013. Joint Commitment: How We Make the Social World. Oxford: Oxford University Press.

Green, Mitchell. 2018. "A Refinement and Defense of the Force/Content Distinction." In New Work on Speech Acts, edited by Daniel Fogal, Daniel W. Harris, and Matt Moss. Oxford: Oxford University Press.

Hanks, Peter. 2015. Propositional Content. Oxford: Oxford University Press.

- 2019. "On Cancellation." Synthese 196 (4): 1385-1402.

Hare, R. M. 1971. Practical Inferences. Berkeley: University of California Press.

König, Ekkehard, and Peter Siemund. 2007. "Speech Act Distinctions in Grammar." Language Typology and Syntactic Description 1: 276-324.

Mill, John Stuart. 1884. A System of Logic Ratiocinative and Inductive: Being a Connected View of the Principles of Evidence and the Methods of Scientific Investigation. Harper.

Recanati, François. 2007. Perspectival Thought: A Plea for Moderate Relativism. Oxford: Oxford University Press. 2019. "Force Cancellation." Synthese 196 (4): 1403-24.

Reiland, Indrek. 2019. "Predication and the Frege-Geach Problem." Philosophical Studies 176 (1): 141-59.

Schmid, Hans Bernhard. 2014a. "Expressing Group Attitudes: On First Person Plural Authority." Erkenntnis 79 (9): 1685-1701. . 2014b. "Plural Self-Awareness." Phenomenology and the Cognitive Sciences 13 (1): 7 24.

. 2017. "What Kind of Mode Is the We-Mode?" In Social Ontology and Collective Intentionality: Critical Essays on the Philosophy of Raimo Tuomela with His Responses, edited by Gerhard Preyer and Georg Peter, 79-94. Cham: Springer International Publishing. http://dx.doi.org/10.1007/978-3-319-33236-9_5.

2018. "The Subject of 'We Intend."' Phenomenology and the Cognitive Sciences 17 (2): 231-243. 
Schmitz, Michael. manuscripta. "Force, Content and the Varieties of Unity." https://philpapers.org/rec/SCHFCA-15.

- manuscriptb. "Questions, Content and the Varieties of Force." https://philpapers.org/rec/SCHQCA-3.

. 2012. "The Background as Intentional, Conscious, and Nonconceptual." In Knowing without Thinking: Mind, Action, Cognition and the Phenomenon of the Background, edited by Zdravko Radman, 57-82.

- 2015. "Joint Attention and Understanding Others." Synthesis Philosophica 58: 235-251.

. 2017. "What Is a Mode Account of Collective Intentionality?” In Social Ontology and Collective Intentionality: Critical Essays on the Philosophy of Raimo Tuomela with His Responses, edited by Gerhard Preyer and Georg Peter, 37-70. Cham: Springer International Publishing.

_ 2018a. "Co-Subjective Consciousness Constitutes Collectives." Journal of Social Philosophy 49 (1): 137-160.

- 2018b. "Force, Content and Logic." In Philosophy of Logic and Mathematics, Contributions of the Austrian Ludwig Wittgenstein Society, Vol. XXVI 41th International Wittgenstein Symposium Kirchberg Am Wechsel, edited by Gabriele M. Mras, Paul Weingartner, and Bernhard Ritter, 221-23. https://philpapers.org/rec/SCHFCA-14.

Searle, John R. 1969. Speech Acts: An Essay in the Philosophy of Language. Cambridge University Press.

1983. Intentionality: An Essay in the Philosophy of Mind. Cambridge University Press.

. 1989. "How Performatives Work." Linguistics and Philosophy 12 (5): 535-558. 1992. The Rediscovery of the Mind. MIT Press.

Soames, Scott. 2015. Retbinking Language, Mind, and Meaning. Princeton University Press. Unger, Peter. 1975. Ignorance: A Case for Scepticism. Oxford: Clarendon Press.

Wilson, Deirdre, and Dan Sperber. 1988. "Mood and the Analysis of Non-Declarative Sentences." In Human Agency: Language, Duty, and Value, edited by J. Dancy, J. M. E. Moravcsik, and C. C. W. Taylor, 77--101. Stanford University Press. 